\title{
Coronary Artery Dominance and Atrial Fibrillation Recurrence after Cryoballoon Pulmonary Vein Isolation
}

\author{
Ahmet Korkmaz, Ilyas Emre Yakıcı, Bekir Demirtaş, Funda Başyigit, Havva Tugba Gursoy, Emrullah Kızıltunc, Ender Ornek, Ozgul Ucar Elalmis, Mehmet Ileri, \\ Umit Güray \\ Department of Cardiology, Ankara Bilkent City Hospital, Ankara, Turkey
}

ORCID:

Ahmet Korkmaz: https://orcid.org/0000-0003-2672-5109

ilyas Emre Yakıcl: https://orcid.org/0000-0003-1137-6233

Bekir Demirtaş: https://orcid.org/0000-0002-6266-2291

Funda Başyigit: https://orcid.org/0000-0002-0341-5346

Havva Tugba Gursoy: https://orcid.org/0000-0002-3892-3930

Emrullah Kızltunc: https://orcid.org/0000-0002-8152-9680

Ender Ornek: https://orcid.org/0000-0002-5233-8658

Ozgul Ucar Elalmıs: https://orcid.org/0000-0001-6932-8440

Mehmet lleri: https://orcid.org/0000-0003-0941-7446

Umit Güray: https://orcid.org/0000-0002-6604-2970

\section{Abstract}

Background and Aim: Catheter-based atrial fibrillation (AF) ablation primarily for pulmonary vein isolation (PVI) has become a significant therapeutic alternative for symptomatic and drug-refractory AF patients. It is evident that AF time and left atrium diameter (LAD) have the most critical impact on AF recurrence. In this study, we aimed to evaluate the role of coronary artery dominance for predicting AF recurrence after cryoballoon PVI. Methods: We retrospectively analyzed clinical, laboratory, and angiographic data from consecutive patients who underwent coronary angiography and successful cryoballoon PVI. Images of the coronary angiography were retrospectively reviewed for the coronary artery dominance by two experienced observers. The coronary artery system was classified as right dominant (RD) and left dominant. Results: A total of 140 patients without coronary artery disease and structural heart disease who underwent successful cryoballoon PVI were included in the study. There were $101 \mathrm{RD}(72 \%)$ and 39 left-dominant (28\%) patterns. A total of 26 patients (22\%) had developed AF recurrence during follow-up. AF recurrence rates were $41 \%$ in the left coronary-dominant group and $15 \%$ in the right coronary-dominant group $(P=0.001)$. According to AF recurrence after cryoballoon PVI, only follow-up time $(15.7 \pm 2.4$ vs. $14 \pm 1.8$ months, $P=0.001)$, LAD $(41.8 \pm 2$ vs. $40.6 \pm 1.8 \mathrm{~mm}, P=0.003)$ and coronary artery disease (CAD) (left CAD, $51.6 \%$ vs. $21.1 \%, P=0.001)$ were significantly associated with $\mathrm{AF}$ recurrence. AF recurrence rates in multivariable logistic regression analysis according to AF recurrence after cryoballoon PVI, follow-up time, $\mathrm{LAD}$, and CAD were independent predictors of AF recurrence. Conclusions: Our findings suggested that left CAD may be related to AF recurrence after cryoballoon PVI. Coronary artery dominance may be an additional predictor of AF recurrence if supported by larger prospective studies.

Keywords: Atrial fibrillation, coronary artery, cryoballoon, dominance, pulmonary vein

\section{INTRODUCTION}

Atrial fibrillation (AF) is the most common type of sustained cardiac arrhythmia in clinical practice. ${ }^{[1]}$ Catheter-based AF ablation, primarily by pulmonary vein isolation (PVI), has

Submission: 26-Jun-19 Revision: 19-Sep-19 Accepted: 27-Sep-19

Published Online: 25-Nov-19

\begin{tabular}{|l|l|}
\hline \multicolumn{3}{|c|}{ Access this article online } \\
\hline Quick Response Code: & Website: \\
& \\
http:/www.ijcva.com
\end{tabular}

Address for correspondence: Dr. Ahmet Korkmaz, Ankara Bilkent City Hospital, Ankara, Turkey. E-mail: drahmtkrkmz07@gmail.com

This is an open access journal, and articles are distributed under the terms of the Creative Commons Attribution-NonCommercial-ShareAlike 4.0 License, which allows others to remix, tweak, and build upon the work non-commercially, as long as appropriate credit is given and the new creations are licensed under the identical terms.

For reprints contact: reprints@medknow.com

How to cite this article: Korkmaz A, Yakıcı IE, Demirtaş B, Başyigit F, Gursoy HT, Kiz1ltunc E, et al. Coronary artery dominance and atrial fibrillation recurrence after cryoballoon pulmonary vein isolation. Int $\mathrm{J}$ Cardiovasc Acad 2019;5:146-51. 
emerged as a promising therapeutic alternative with improved efficacy and safety in symptomatic and drug-refractory AF patients. ${ }^{[2]}$ Although there has been a significant improvement in procedural success through the use of recently developed ablation techniques, postprocedural AF recurrences continue to be a major clinical problem following catheter ablation, occurring in approximately $25 \%-50 \%$ of patients. ${ }^{[3]}$

Anatomical coronary dominance is defined based on the origin of the posterior descending artery (PDA) that supplies the posterior portion of the interventricular septum. ${ }^{[4,5]}$ In a right-dominant (RD) circulation, the right coronary artery (RCA) gives off the PDA, while in a left-dominant (LD) circulation, the left circumflex (LCX) artery supplies this territory. ${ }^{[4,5]}$ In the present study, we evaluate the relationship between coronary arterial dominance and $\mathrm{AF}$ recurrence after cryoballoon ablation (CA).

\section{Methods}

We analyzed retrospectively clinical, laboratory, and angiographic data of consecutive patients who underwent a coronary angiography and a successful CA for 12-lead confirmed, symptomatic, and drug-refractory paroxysmal AF. Patients whose episodes of AF terminated spontaneously within 7 days of onset were defined as having paroxysmal AF.

Patients with valvular disease, a thrombus in the left atrium (LA), thyroid dysfunction, preprocedural significant coronary artery stenosis, myocardial infarction, previous cardiac surgery, contraindication to anticoagulation, pregnancy, and an LA diameter (LAD) $>50 \mathrm{~mm}$ were excluded from the study, along with subjects with recent infections, malignancies, blood dyscrasias, autoimmune or inflammatory diseases, renal failure, or hepatic failure.

The recorded patient data, accessed from the records from the time of CA, included both clinical and demographic characteristics, including age, gender, history of arterial hypertension (HT), diabetes mellitus (DM) and tobacco use, and echocardiographic parameters.

Periprocedural interventions related to the catheter CA were performed as outlined in the current guidelines and studies. ${ }^{[3,6,7]}$ The study participants continued to receive the anticoagulation and antiarrhythmic drug regimen prescribed prior to the ablation procedure for the following 3 months. When the patients developed symptoms compatible with recurrent $\mathrm{AF}$, follow-up visits were made in the $3^{\text {rd }}, 6^{\text {th }}$, and $12^{\text {th }}$ months and then at most every 6 months afterward. In the postprocedural $3^{\text {rd }}$ month, a 24-48-h Holter electrocardiograph (ECG) was made, and antiarrhythmic treatment was ceased if no arrhythmia was detected. At the $3^{\text {rd }}$ month and every 6 months thereafter, another 24-48-h Holter ECG was performed and recorded. The requirement for oral anticoagulation was also assessed after the $3^{\text {rd }}$ month, based on the CHA2DS2-VASc score. ${ }^{[8]}$ The time from the date of ablation to the date of recurrence or the last follow-up was used to calculate the
AF-free period. The blanking period was defined as the first 3 months following AF ablation. No atrial arrhythmias that arose during the blanking period were defined as a recurrence. The detection of AF (at least $30 \mathrm{~s}$ when evaluated with ECG or Holter ECG monitoring) occurring more than 3 months after the $\mathrm{AF}$ ablation procedure was used to define $\mathrm{AF}$ recurrence.

Images of the coronary angiography were obtained using standardized angiographic projections, based on the guidelines of the American College of Cardiology/American Heart Association, and stored digitally. ${ }^{[9]}$ All images were reviewed retrospectively for coronary dominance by two experienced observers. The coronary artery system was classified as RD if the RCA gave off the PDA and as LD if the LCX supplied this territory. Significant coronary artery disease (CAD) was defined as a $\geq 50 \%$ narrowing of luminal diameter in at least one projection of at least one major epicardial artery, and these subjects were excluded.

The study was in compliance with the principles outlined in the Declaration of Helsinki and approved by the institutional ethics committee.

\section{Statistical analysis}

The normality of distribution of all study parameters was evaluated. For the comparison of continuous data with normal distribution, a Student's $t$-test was used. A Mann-Whitney U-test was used to compare data with skewed distribution. AChi-square test was used to compare categorical variables. Continuous variables are presented as mean $\pm \mathrm{SD}$, whereas categorical data are presented as percentages. To clarify the clinical predictors of outcomes, a univariate Cox proportional analysis was performed initially. Sequentially, all variables with $P<0.10$ in the univariate analyses were included in a multivariate analysis, and hazard ratios and $95 \%$ confidence intervals were calculated. For all tests, a two-tailed $P<0.05$ was considered statistically significant. The statistical analysis made using SPSS version 20.0 software (IBM Corp., Armonk, NY, USA).

\section{REsULTS}

A total of 140 patients without significant CAD who underwent $\mathrm{CA}$ for AF were included. The mean age of the cohort was $41.8 \pm 7.8$ years; $59 \%$ were men; $13 \%$ had diabetes; $38 \%$ had HT; and $27 \%$ were smokers. Of the 140 patients enrolled in the study, 31 (22\%) had AF recurrence, 101 (72\%) had RD circulation, and $39(28 \%)$ had LD circulation. The baseline characteristic features of the study population are presented in Table 1.

The patients were divided into two groups, based on the recurrence of AF. There were no significant differences between the two groups in the mean age; gender ratio; mean body mass index (BMI); smoking rate; or frequency of DM, HT, or hyperlipidemia. No significant difference was detected in any other baseline laboratory parameters. LAD was larger in the AF recurrence group than that in the AF nonrecurrence group $(41.8 \pm 2.0 \mathrm{~mm}$ vs. $40.6 \pm 1.8 \mathrm{~mm}$, $P=0.003$ ). Similarly, when compared to the AF nonrecurrence 


\begin{tabular}{|c|c|c|c|}
\hline & Minimum-Maximum & Median & Mean \pm SD $/ n(\%)$ \\
\hline Age & $19.0-63.0$ & 43.0 & $41.8 \pm 7.8$ \\
\hline \multicolumn{4}{|l|}{ Sex } \\
\hline Female & & & $57(41)$ \\
\hline Male & & & $83(59)$ \\
\hline BMI & $21.3-34.6$ & 28.9 & $29.4 \pm 4.3$ \\
\hline \multicolumn{4}{|l|}{ Coronary dominance } \\
\hline Right & & & $101(72)$ \\
\hline Left & & & $39(28)$ \\
\hline Smoking & & & $38(27)$ \\
\hline $\mathrm{DM}$ & & & $18(13)$ \\
\hline HT & & & $53(38)$ \\
\hline \multicolumn{4}{|l|}{ Recurrence } \\
\hline Yes & & & $31(22)$ \\
\hline No & & & $109(78)$ \\
\hline $\mathrm{LAD}, \mathrm{mm}$ & $37.0-47.0$ & 40.0 & $40.8 \pm 1.9$ \\
\hline Follow-up time & $12.0-20.0$ & 14.0 & $14.4 \pm 2.1$ \\
\hline $\mathrm{WBC}, \times 10^{9} / \mathrm{L}$ & 4.1-14.2 & 7.1 & $7.4 \pm 2.0$ \\
\hline Neutrophil, $\times 10^{9} / \mathrm{L}$ & $1.9-11.2$ & 4.4 & $4.5 \pm 1.5$ \\
\hline Lymphocytes, $\times 10^{9} / \mathrm{L}$ & $1.0-6.6$ & 2.2 & $2.4 \pm 0.9$ \\
\hline $\mathrm{Hgb}, \mathrm{g} / \mathrm{dL}$ & $9.6-18$ & 13.9 & $14.1 \pm 1.5$ \\
\hline $\mathrm{PLT}, \times 10^{9} / \mathrm{L}$ & $122-472$ & 262 & $267 \pm 65$ \\
\hline Glucose, mg/dL & $81-373$ & 96 & $98 \pm 28$ \\
\hline Creatinine, $\mathrm{mg} / \mathrm{dL}$ & $0.5-1.2$ & 0.8 & $0.8 \pm 0.1$ \\
\hline Total protein, $\mathrm{g} / \mathrm{dL}$ & $5.8-8.5$ & 7.4 & $7.4 \pm 0.5$ \\
\hline Albumin, $\mathrm{g} / \mathrm{dL}$ & $3.7-5.1$ & 4.5 & $4.5 \pm 0.3$ \\
\hline $\mathrm{TG}, \mathrm{mg} / \mathrm{dL}$ & $70-760$ & 144 & $180 \pm 144$ \\
\hline Total cholesterol, mg/dL & $101-360$ & 200 & $202 \pm 48$ \\
\hline $\mathrm{HDL}, \mathrm{mg} / \mathrm{dL}$ & $28-77$ & 47 & $47 \pm 11$ \\
\hline $\mathrm{LDL}, \mathrm{mg} / \mathrm{dL}$ & $58-255$ & 118.0 & $120 \pm 38$ \\
\hline NLR & $0.8-6.2$ & 20 & $2.0 \pm 0.8$ \\
\hline PLR & $43-286$ & 20 & $120 \pm 41$ \\
\hline
\end{tabular}

BMI: Body mass index; DM: Diabetes mellitus, HT: Hypertension, Hgb: Hemoglobin, HDL-C: High-density lipoprotein cholesterol, LDL-C: Low-density lipoprotein cholesterol, LAD: Left atrium diameter, NLR: Neutrophil-to-lymphocyte ratio, PLT: Platelet, PLR: Platelet-to-lymphocyte ratio, TG: Triglyceride, WBC: White blood count, SD: Standard deviation

group, the follow-up period was longer in the AF recurrence group $(14.0 \pm 1.8$ months vs. $15.7 \pm 2.4$ months, $P=0.001)$. A comparison of the baseline characteristics and laboratory parameters of the $\mathrm{AF}$ recurrence and $\mathrm{AF}$ nonrecurrence groups is presented in Table 2 .

In the AF recurrence group, LD circulation was observed in 16 cases $(51.6 \%)$ and RD circulation was observed in 15 cases $(48.4 \%)$. RD circulation was significantly more common than LD circulation in the AF nonrecurrence group (86 cases [78.9\%] vs. 23 cases [21.1\%], respectively, $P=0.001)$. The rate of $\mathrm{LD}$ circulation correlated significantly with $\mathrm{AF}$ recurrence [Table 3 and Figure 1]. In the multivariate logistic regression analysis, LD circulation, LAD, and duration of follow-up were independent predictors of $\mathrm{AF}$ recurrence $(P<0.05)$ [Table 4].

\section{DisCussion}

The findings of the present study suggest an association between LD circulation and AF recurrence after PVI CA.

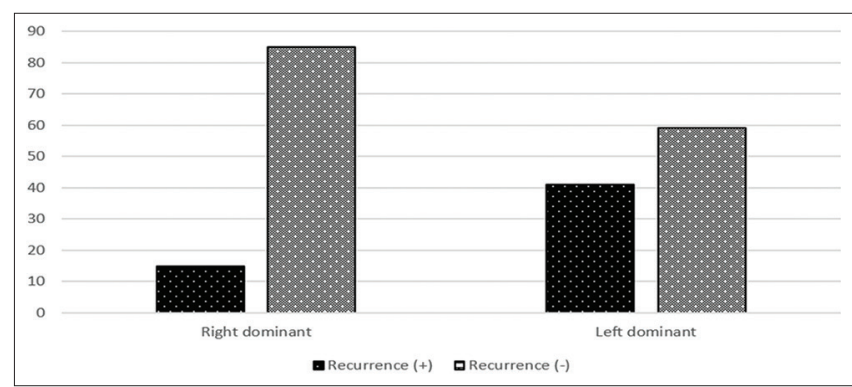

Figure 1: The relationship between coronary artery dominance and recurrence of paroxysmal atrial fibrillation after cryoballoon pulmonary vein isolation

Moreover, a larger LAD and a longer follow-up time were identified as other independent predictors of AF recurrence. In the present study, the rate of recurrence after CA was $22 \%$, which is similar to the results of other studies. ${ }^{[10-12]}$

Previous studies indicate that several factors, including age, $\mathrm{HT}$, duration of AF, early recurrence of AF, obesity, LAD, 


\begin{tabular}{|c|c|c|c|c|c|}
\hline & \multicolumn{2}{|c|}{ Recurrence $(+)(n=31)$} & \multicolumn{2}{|c|}{ Recurrence $(-)(n=109)$} & \multirow[t]{2}{*}{$P$} \\
\hline & Mean $\pm S D / n(\%)$ & Median & Mean \pm SD/n (\%) & Median & \\
\hline Age & $42.6 \pm 5.9$ & 42 & $41.6 \pm 8.3$ & 43 & $0.850(\mathrm{M})$ \\
\hline \multicolumn{6}{|l|}{ Sex } \\
\hline Female & $15(48.4)$ & & $42(38.5)$ & & $0.324 \chi^{2}$ \\
\hline Male & $16(51.6)$ & & $67(61.5)$ & & \\
\hline BMI & $30.3 \pm 3.7$ & 29.7 & $29.2 \pm 4.4$ & 27.8 & $0.070(\mathrm{M})$ \\
\hline \multicolumn{6}{|l|}{ Coronary dominance } \\
\hline Right & $15(48.4)$ & & $86(78.9)$ & & $0.001\left(\chi^{2}\right)$ \\
\hline Left & $16(51.6)$ & & $23(21.1)$ & & \\
\hline Smoking & $7(22.6)$ & & $31(28.4)$ & & $0.517\left(\chi^{2}\right)$ \\
\hline DM & $2(6.5)$ & & $16(14.7)$ & & $0.217\left(\chi^{2}\right)$ \\
\hline HT & $10(32.3)$ & & $43(39.4)$ & & $0.466\left(\chi^{2}\right)$ \\
\hline $\mathrm{LAD}, \mathrm{mm}$ & $41.8 \pm 2.0$ & 42.0 & $40.6 \pm 1.8$ & 40.0 & $0.003(\mathrm{M})$ \\
\hline Follow-up time, months & $15.7 \pm 2.4$ & 15.0 & $14.0 \pm 1.8$ & 14.0 & $0.001(\mathrm{M})$ \\
\hline $\mathrm{WBC}, \times 10^{9} / \mathrm{L}$ & $7.6 \pm 1.9$ & 7.1 & $7.4 \pm 2.1$ & 7.2 & $0.547(\mathrm{M})$ \\
\hline Neutrophil, $\times 10^{9} / \mathrm{L}$ & $4.7 \pm 1.4$ & 4.6 & $4.5 \pm 1.5$ & 4.2 & $0.221(\mathrm{M})$ \\
\hline Lymphocytes, $\times 10^{9} / \mathrm{L}$ & $2.6 \pm 0.8$ & 2.5 & $2.4 \pm 0.9$ & 2.1 & $0.073(\mathrm{M})$ \\
\hline $\mathrm{Hgb}, \mathrm{g} / \mathrm{dL}$ & $14.1 \pm 1.3$ & 14.4 & $14.0 \pm 1.6$ & 13.7 & $0.511(\mathrm{M})$ \\
\hline $\mathrm{PLT}, \times 10^{9} / \mathrm{L}$ & $263 \pm 61$ & 258 & $268 \pm 67$ & 263 & $0.648(\mathrm{M})$ \\
\hline Glucose, $\mathrm{mg} / \mathrm{dL}$ & $93 \pm 19$ & 96 & $99 \pm 29$ & 95.0 & $0.530(\mathrm{M})$ \\
\hline Creatinine, $\mathrm{mg} / \mathrm{dL}$ & $0.8 \pm 0.1$ & 0.9 & $0.8 \pm 0.1$ & 0.8 & $0.239(\mathrm{M})$ \\
\hline Total protein, g/dL & $7.3 \pm 0.4$ & 7.4 & $7.4 \pm 0.5$ & 7.4 & $0.337(t)$ \\
\hline Serum albumin, $\mathrm{g} / \mathrm{dL}$ & $4.4 \pm 0.3$ & 4.3 & $4.5 \pm 0.3$ & 4.5 & $0.076(\mathrm{M})$ \\
\hline $\mathrm{TG}, \mathrm{mg} / \mathrm{dL}$ & $163 \pm 69$ & 151 & $185 \pm 59$ & 139 & $0.962(\mathrm{M})$ \\
\hline Total cholesterol, mg/dL & $208 \pm 54$ & 193 & $200 \pm 46$ & 200 & $0.646(\mathrm{M})$ \\
\hline $\mathrm{HDL}, \mathrm{mg} / \mathrm{dL}$ & $48.8 \pm 12.6$ & 46 & $46.9 \pm 10.8$ & 47 & $0.614(\mathrm{M})$ \\
\hline $\mathrm{LDL}, \mathrm{mg} / \mathrm{dL}$ & $126.5 \pm 43.7$ & 121 & $117.9 \pm 36.1$ & 118 & $0.462(\mathrm{M})$ \\
\hline NLR & $2.0 \pm 0.7$ & 2.0 & $2.0 \pm 7$ & 1.8 & $0.681(\mathrm{M})$ \\
\hline PLR & $110.4 \pm 42$ & 107 & $122.2 \pm 0.9$ & 118 & $0.054(\mathrm{M})$ \\
\hline
\end{tabular}

$t=T$-test, $\mathrm{M}=$ Mann-Whitney U-test, $\chi^{2}=$ Chi-squared test. BMI: Body mass index, DM: Diabetes mellitus, HT: Hypertension, Hgb: Hemoglobin, HDL-C: High density lipoprotein cholesterol, LDL-C: Low density lipoprotein cholesterol, LAD: Left atrium diameter, NLR: Neutrophil-to-lymphocyte ratio, PLT: Platelet, PLR: Platelet-to-lymphocyte ratio, TG: Triglyceride, WBC: White blood count

\begin{tabular}{lccc}
\hline $\begin{array}{l}\text { Table 3: The relationship between coronary artery } \\
\text { dominance and recurrence of paroxysmal AF after } \\
\text { cryoballoon PVI }\end{array}$ & \\
\hline & $\begin{array}{c}\text { Recurrence(+) } \\
\boldsymbol{n}=\mathbf{3 1}(\mathbf{2 2} \%)\end{array}$ & $\begin{array}{c}\text { Recurrence(-) } \\
\boldsymbol{n}=\mathbf{1 0 9}(\mathbf{7 8 \%})\end{array}$ & $\begin{array}{c}\boldsymbol{P} \\
\text { value }\end{array}$ \\
\hline $\begin{array}{l}\text { Right coronary } \\
\text { dominance } \\
n=101,(72 \%)\end{array}$ & $15(15 \%)$ & $86(85 \%)$ & \\
$\begin{array}{l}\text { Left coronary } \\
\text { dominance } \\
n=39,(28 \%)\end{array}$ & $16(41 \%)$ & $23(59 \%)$ & 0.001 \\
\hline
\end{tabular}

inflammation, and LA fibrosis (determined by magnetic resonance imaging), are predictors of AF recurrence. ${ }^{[10,12-14]}$ In the present study, LD circulation was found to be associated with AF recurrence in patients who underwent PVI CA for paroxysmal AF. In addition, in line with the findings of previous studies, LAD and a longer follow-up time were identified as independent predictors of AF recurrence also in the present study. However, we found no association between AF recurrence and demographic data such as age, HT, DM or BMI, or inflammatory markers such as neutrophil/ lymphocyte ratio, platelet/lymphocyte ratio, and albumin. In our study, similar to some previous studies, ${ }^{[7,10,11]}$ gender and smoking were not associated with AF recurrence. However, there are studies in the literature that smoking and female gender are independent predictors of AF recurrence. ${ }^{[15-17]}$ This inconsistency may be due to the age of the patients in our study being younger than other studies. In addition, this inconsistency could be explained by the fact that our study consisted of only paroxysmal AF patients and its small and retrospective design. Further studies are warranted to confirm and assess the possible mechanisms of these links.

Previous studies indicate that RCA is dominant in $85 \%$ of patients, while about half of the remaining $15 \%$ appear to have left coronary artery (LCA)-dominant circulation. ${ }^{[18]}$ Previous studies also suggest a prognostic association between coronary artery dominance and $\mathrm{CAD}$, acute ST-elevation myocardial infarction (STEMI), and chronic total coronary artery occlusion. ${ }^{[19-21]}$ Although the available data are inconclusive, 


\begin{tabular}{|c|c|c|c|}
\hline \multicolumn{4}{|c|}{$\begin{array}{l}\text { Table 4: Multivariate logistic regression analysis showing } \\
\text { independent predictors of atrial fibrillation recurrence } \\
\text { after cryoballoon pulmonary vein isolation }\end{array}$} \\
\hline Variables & Odds ratio & $95 \% \mathrm{Cl}$ & $P$ \\
\hline PLR & 0.840 & $0.650-1.250$ & 0.358 \\
\hline Albumin & 0.753 & $0.135-4.215$ & 0.747 \\
\hline LAD & 1.670 & $1.266-2.203$ & $<0.001$ \\
\hline Follow-up time & 1.518 & $1.182-1.950$ & 0.001 \\
\hline Coronary dominance & 5.701 & $1.994-16.301$ & 0.001 \\
\hline
\end{tabular}

LAD: Left atrium diameter, PLR: Platelet-to-lymphocyte ratio,

CI: Confidence interval

previous studies involving patients who underwent PCI demonstrated that LD was associated with increased risk of death or re-infarction during long-term follow-up. ${ }^{[22-24]}$ Similarly, patients with an LD or codominant coronary artery system had lower left ventricular ejection fraction early after STEMI. ${ }^{[2,26]} \mathrm{An}$ LD coronary artery tree may have a less well-balanced circulation than other systems, resulting in a larger area of myocardium at risk in the face of various cardiovascular diseases. In patients with LD, blood supply to the sinoatrial node may be disturbed and may predispose patients to arrhythmias such as AF.

A P-wave duration (PWD) in sinus rhythm preablation has been hypothesized to be a noninvasive ECG marker associated with increased AF recurrence after PVI. ${ }^{[27,28]}$ There is a newer study showed that prolonged PWD with a cutoff of $>120 \mathrm{~ms}$ to $>150 \mathrm{~ms}$ in sinus rhythm before ablation may be associated with AF recurrence after PVI regardless of age, gender, left atrial size, and the presence of structural heart disease. ${ }^{[29]}$ Nabi Aslan et al. investigated the relationship between coronary dominance and AF from PWD and P-wave dispersion in a previous study. ${ }^{[30]}$ At the end of their study, they suggested that atrial blood flow may depend mainly on the RCA, as the RCA territory is relatively weak in LD patients, and left dominancy may increase the risk of $A F \cdot{ }^{[30]}$ Likewise, in the present study, $\mathrm{AF}$ recurrence was more common in patients with LD circulation than in patients with RD circulation, leading us to hypothesize that blood supply to the sinoatrial node is disturbed in patients with LD circulation.

Blood flow within a coronary branch located close to an radiofrequency $(\mathrm{RF})$ electrode renders a protective effect via convective cooling, hindering RF energy from overheating the vascular endothelium, ${ }^{[31]}$ and this "heat sink" protects the coronary arteries. On the other hand, it may also limit the success of ablation procedures as a result of the "shadow effect" phenomenon. It is thought that blood flow through the small intramyocardial vessels may disrupt the formation of transmural lesions, may preserve conduction through an RF lesion, and in this way, may prevent complete conduction block. ${ }^{[32,33]}$ In the present study, AF ablation was achieved through CA rather than RF, although similar mechanisms may have taken place in both procedures. The arteries supplying the LA are among the earliest branches of the LCA, usually from the LCX. ${ }^{[34]}$ We suggest that better circulation of the LA may be seen in patients with LD circulation, thus preventing the success of CA. This may be the reason why AF recurrence is more common in patients with $\mathrm{LD}$ circulation.

\section{Study limitations}

Our study had several limitations. First, the study was performed in a single center and included only paroxysmal AF patients. The second limitation is the fact that although follow-up visits and questioning of symptoms were performed and all participants underwent 24-48-h Holter monitoring, some patients with recurrent AF may have been overlooked. Finally, the sample size was relatively small and the retrospective design of the study does not make it possible to draw conclusions about cause-effect relationship.

\section{Conclusions}

The findings of the present study suggest an increased risk of AF recurrence after PVI CA in patients with left-dominant coronary artery circulation. Coronary artery dominance may be considered an additional predictor of $\mathrm{AF}$ recurrence, provided that the findings of the present study can be confirmed in future prospective controlled studies.

\section{Financial support and sponsorship}

Nil.

\section{Conflicts of interest}

There are no conflicts of interest.

\section{ReFERENCES}

1. Miyasaka Y, Barnes ME, Gersh BJ, Cha SS, Bailey KR, Abhayaratna WP, et al. Secular trends in incidence of atrial fibrillation in Olmsted county, Minnesota, 1980 to 2000 , and implications on the projections for future prevalence. Circulation 2006;114:119-25.

2. Camm AJ, Kirchhof P, Lip GY, Schotten U, Savelieva I, Ernst S, et al. Guidelines for the management of atrial fibrillation: The task force for the management of atrial fibrillation of the European Society of Cardiology (ESC). Europace 2010;12:1360-420.

3. Calkins H, Kuck KH, Cappato R, Brugada J, Camm AJ, Chen SA, et al. $2012 \mathrm{HRS} / \mathrm{EHRA} / \mathrm{ECAS}$ expert consensus statement on catheter and surgical ablation of atrial fibrillation: Recommendations for patient selection, procedural techniques, patient management and follow-up, definitions, endpoints, and research trial design. Europace 2012;14:528-606.

4. Allwork SP. The applied anatomy of the arterial blood supply to the heart in man. J Anat 1987;153:1-6.

5. Omerbasic E, Hasanovic A, Omerbasic A, Pandur S. Prognostic value of anatomical dominance of coronary circulation in patients with surgical myocardial revascularization. Med Arch 2015;69:6-9.

6. Oto A, Aytemir K, Canpolat U, Karakulak U, Evranos B, Sahiner L, et al. Pulmonary vein isolation with the cryoballoon technique in atrial fibrillation treatment: Single centre experience. Turk Kardiyol Dern Ars 2013;41:299-309.

7. Canpolat U, Aytemir K, Yorgun H, Şahiner L, Kaya EB, Kabakçı G, et al. Role of preablation neutrophil/lymphocyte ratio on outcomes of cryoballoon-based atrial fibrillation ablation. Am J Cardiol 2013;112:513-9.

8. Kirchhof P, Benussi S, Kotecha D, Ahlsson A, Atar D, Casadei B, et al. 2016 ESC guidelines for the management of atrial fibrillation developed in collaboration with EACTS. Eur Heart J 2016;37:2893-962.

9. Scanlon PJ, Faxon DP, Audet AM, Carabello B, Dehmer GJ, Eagle KA, et al. ACC/AHA guidelines for coronary angiography. A report of the 
American College of Cardiology/American Heart Association task force on practice guidelines (Committee on Coronary Angiography). Developed in collaboration with the Society for Cardiac Angiography and Interventions. J Am Coll Cardiol 1999;33:1756-824.

10. Aksu T, Baysal E, Guler TE, Golcuk SE, Erden İ, Ozcan KS, et al. Predictors of atrial fibrillation recurrence after cryoballoon ablation. J Blood Med 2015;6:211-7.

11. Canpolat U, Aytemir K, Yorgun H, Şahiner L, Kaya EB, Çay S, et al. Usefulness of serum uric acid level to predict atrial fibrillation recurrence after cryoballoon-based catheter ablation. Europace 2014;16:1731-7.

12. Quan D, Huang H, Kong B, Li Q, Liao J, Wang G. Predictors of late atrial fibrillation recurrence after cryoballoon-based pulmonary vein isolation: A meta-analysis. Kardiol Pol 2017;75:376-85.

13. Berruezo A, Tamborero D, Mont L, Benito B, Tolosana JM, Sitges M, et al. Pre-procedural predictors of atrial fibrillation recurrence after circumferential pulmonary vein ablation. Eur Heart J 2007;28:836-41.

14. D'Ascenzo F, Corleto A, Biondi-Zoccai G, Anselmino M, Ferraris F, di Biase L, et al. Which are the most reliable predictors of recurrence of atrial fibrillation after transcatheter ablation? A meta-analysis. Int J Cardiol 2013;167:1984-9.

15. Fukamizu S, Sakurada H, Takano M, Hojo R, Nakai M, Yuba T, et al. Effect of cigarette smoking on the risk of atrial fibrillation recurrence after pulmonary veinisolation. J Arrhythm 2010;26:21-9.

16. Kosiuk J, Dinov B, Kornej J, Acou WJ, Schönbauer R, Fiedler L, et al. Prospective, multicenter validation of a clinical risk score for left atrial arrhythmogenic substrate based on voltage analysis: DR-FLASH score. Heart Rhythm 2015;12:2207-12.

17. Mesquita J, Ferreira AM, Cavaco D, Moscoso Costa F, Carmo P, Marques $\mathrm{H}$, et al. Development and validation of a risk score for predicting atrial fibrillation recurrence after a first catheter ablation procedure - ATLAS score. Europace 2018;20:f428-f435.

18. Zipes DP, Libby P, Bonow RO. Braunwald's Heart Disease: A Textbook of Cardiovascular Medicine. $7^{\text {th }}$ ed. Philadelphia: WB. Saunders. 2005. p. 430-6.

19. Vasheghani-Farahani A, Kassaian SE, Yaminisharif A, Davoodi G, Salarifar M, Amirzadegan A, et al. The association between coronary arterial dominancy and extent of coronary artery disease in angiography and paraclinical studies. Clin Anat 2008;21:519-23.

20. Veltman CE, van der Hoeven BL, Hoogslag GE, Boden $H$, Kharbanda RK, de Graaf MA, et al. Influence of coronary vessel dominance on short- and long-term outcome in patients after ST-segment elevation myocardial infarction. Eur Heart J 2015;36:1023-30.

21. Gebhard C, Gick M, Ferenc M, Stähli BE, Ademaj F, Mashayekhi K, et al. Coronary dominance and prognosis in patients with chronic total occlusion treated with percutaneous coronary intervention. Catheter Cardiovasc Interv 2018;91:669-78.

22. Goldberg A, Southern DA, Galbraith PD, Traboulsi M, Knudtson ML, Ghali WA. Coronary dominance and prognosis of patients with acute coronary syndrome. Am Heart J 2007;154:1116-22.
23. Abu-Assi E, Castiñeira-Busto $\mathrm{M}$, González-Salvado V, Raposeiras-Roubin S, Riziq-Yousef Abumuaileq R, Peña-Gil C, et al. Coronary artery dominance and long-term prognosis in patients with ST-segment elevation myocardial infarction treated with primary angioplasty. Rev Esp Cardiol (Engl Ed) 2016;69:19-27.

24. Lam MK, Tandjung K, Sen H, Basalus MW, van Houwelingen KG, Stoel MG, et al. Coronary artery dominance and the risk of adverse clinical events following percutaneous coronary intervention: Insights from the prospective, randomised TWENTE trial. EuroIntervention 2015;11:180-7.

25. Parikh NI, Honeycutt EF, Roe MT, Neely M, Rosenthal EJ, Mittleman MA, et al. Left and codominant coronary artery circulations are associated with higher in-hospital mortality among patients undergoing percutaneous coronary intervention for acute coronary syndromes: Report from the national cardiovascular database cath percutaneous coronary intervention (CathPCI) registry. Circ Cardiovasc Qual Outcomes 2012;5:775-82.

26. Veltman CE, Hoogslag GE, Kharbanda RK, de Graaf MA, van Zwet EW, van der Hoeven BL, et al. Relation between coronary arterial dominance and left ventricular ejection fraction after ST-segment elevation acute myocardial infarction in patients having percutaneous coronary intervention. Am J Cardiol 2014;114:1646-50.

27. Caldwell J, Koppikar S, Barake W, Redfearn D, Michael K, Simpson C, et al. Prolonged $\mathrm{P}$-wave duration is associated with atrial fibrillation recurrence after successful pulmonary vein isolation for paroxysmal atrial fibrillation. J Interv Card Electrophysiol 2014;39:131-8.

28. Salah A, Zhou S, Liu Q, Yan H. P wave indices to predict atrial fibrillation recurrences post pulmonary vein isolation. Arq Bras Cardiol 2013;101:519-27.

29. Pranata R, Yonas E, Vania R. Prolonged P-wave duration in sinus rhythm pre-ablation is associated with atrial fibrillation recurrence after pulmonary vein isolation-A systematic review and meta-analysis. Ann Noninvasive Electrocardiol 2019:e12653.

30. Nabi Aslan A, Baştuğ S, Ahmet Kasapkara H, Can Güney M, Sivri S, Bozkurt E. Coronary artery dominance may predict future risk of atrial fibrillation. Acta Cardiol Sin 2018;34:344-51.

31. Chatelain P, Zimmermann M, Weber R, Campanini C, Adamec R. Acute coronary occlusion secondary to radiofrequency catheter ablation of a left lateral accessory pathway. Eur Heart J 1995;16:859-61.

32. Viles-Gonzalez JF, de Castro Miranda R, Scanavacca M, Sosa E, d'Avila A. Acute and chronic effects of epicardial radiofrequency applications delivered on epicardial coronary arteries. Circ Arrhythm Electrophysiol 2011;4:526-31.

33. Castaño A, Crawford T, Yamazaki M, Avula UM, Kalifa J. Coronary artery pathophysiology after radiofrequency catheter ablation: Review and perspectives. Heart Rhythm 2011;8:1975-80.

34. Boppana VS, Castaño A, Avula UM, Yamazaki M, Kalifa J. Atrial coronary arteries: Anatomy and atrial perfusion territories. J Atr Fibrillation 2011;4:375. 